\title{
Analisis Sebaran Radiasi Hambur Di Sekitar Pesawat Sinar-X Pada Pemeriksaan Tomografi Ginjal
}

\author{
Rini Anggarini' ${ }^{1}$, Muzilman Muslim ${ }^{1}$, Ari Mutanto ${ }^{1}$ \\ ${ }^{1}$ Universitas Nasional, Jalan Sawo Manila, Pejaten, Pasar Minggu Jakarta Selatan 12520 \\ korepondensi : muzilman@gmail.com
}

\begin{abstract}
Abstrak. Telah dilakukan penelitian pengaruh variasi jarak antara sumber radiasi dengan titik pengukuran terhadap sebaran radiasi hambur pada pesawat sinar-X pada saat pemeriksaan tomografi ginjaldi Rumah Sakit Pusat Angkatan Darat Gatot Soebroto sehingga dihasilkan kontur sebaran radiasi hambur dengan menggunakan perangkat lunak surfer.Penelitian ini menggunakan phantom abdomen dengan kondisi penyinaran faktor eksposi tetap meliputi tegangan tabung $70 \mathrm{kV}$, arus tabung dan waktu penyinaran $50 \mathrm{mAs}$. Sampel dalam penelitian adalah jarak $50 \mathrm{~cm}, 100 \mathrm{~cm}$, dan $150 \mathrm{~cm}$ dari titik tengah pusat pemeriksaan ke titik pengukuran. Pengukuran ini dilakukan dengan alat ukur termoluminesensi dosimeter (TLD-100 LiF). Hasil penelitian menunjukkan bahwa jumlah paparan radiasi akan semakin menurun terhadap penambahan jarak, sehingga dapat mengetahui titik-titik / tempat yang aman terhadap paparan radiasi.
\end{abstract}

Kata kunci : Tomografi ginjal, surfer, paparan radiasi hambur, jarak, TLD

\begin{abstract}
It have been conducted research about the influence of distance variability between radiation source and the determining spot to scatter radiation exposure of renal tomography examination at Gatot Soebroto Centre Army Hospital, from that obtained radiation distribution countur by surfer software. This research used abdomen phantom by using fixed expose factor including of tube voltage $70 \mathrm{kV}$, tube current and exposure time $50 \mathrm{mAs}$. Samples in this research are distance $50 \mathrm{~cm}, 100 \mathrm{~cm}$ and $150 \mathrm{~cm}$ from central point of the examination to the determining spot, which measuring the scatter radiation exposure conducted by thermoluminesences dosimeters instrument (TLD-100 LiF). The result of this research indicates that amount of scatter radiation exposure decrease gradually to addition distance. This research can show the point/places that safe from scatter radiation exposure during the examination.
\end{abstract}

Keywords: Renal tomography, surfer, distribution radiation, distance, TLD

\section{PENDAHULUAN}

Salah satu jenis pemeriksaan dengan pemanfaatan sinar-X diagnostik adalah pemeriksaan tomografi.Pemeriksaan dengan teknik tomografi merupakan salah satu teknik radiografi dengan memanfaatkan pergerakan tabung dan kaset secara berlawanan arah yang nantinya menghasilkan gambaran radiografi dengan pengaburan lapisan atas dan bawah dari organ sekitar [1]. Teknik ini umumnya digunakan untuk organ yang terletak superposisi dengan struktur lainnya seperti ginjal. Teknik tomografi ini baik sekali untuk memperlihatkan kontur dari ginjal.

Sinar-X memiliki panjang gelombang yang pendek sehingga tidak dapat dilihat oleh mata selain itu, memiliki energi yang sangat besar. Pemancaran energi pada sinar-X disebut radiasi karena pemancaran energinya dalam bentuk partikel ataupun gelombang.Karena sinar- $\mathrm{X}$ memiliki energi yang sangat besar maka dapat mengionisasi objek atau bahan yang dilewatinya karena itu sinar-X merupakan radiasi pengion. Selain dapat mengionisasi, radiasi sinar-X ketika melewati atau menembus objek dapat mengalami hamburan (scattering). Radiasi terdiri atas radiasi primer dan radiasi hamburan. Radiasi primer adalah radiasi yang berjalan dari tabung sinar-X, kemudian radiasi yang dihasilkan ketika melalui pasien (objek) dengan tidak mengalami perubahan arah namun jumlahnya berkurang disebut radiasi sekunder.Sedangkan radiasi hambur adalah radiasi yang keluar dari obyek dan tidak searah dengan sinar primernya.

Aplikasi dari pemancaran sinar-X ini selain dapat memberikan manfaat yang sangat besar dapat pula mendatangkan ancaman bahaya radiasi yang perlu diwaspadai. Efek yang merugikan dari 
radiasi dapat muncul apabila tubuh manusia mendapatkan paparan radiasi dengan dosis yang berlebihan.Untuk keperluan medis, sumber radiasi sebetulnya sudah didesain sedemikian rupa sehingga aman.Meskipun demikian, peluang terjadinya penyinaran terhadap pekerja tetap masih ada.Karena mengandung resiko tersebut maka ada berbagai upaya yang harus dilakukan sesuai dengan peraturan yang berlaku untuk mengurangi atau meniadakan resiko tersebut. Salah satunya dengan melakukan pemetaan laju dosis radiasi. Kegiatan ini pada prinsipnya perlu dilakukan di setiap fasilitas atau ruangan yang ada sumber radiasinya. Tomografi adalah teknik radiografi untuk memperlihatkan struktur anatomi dengan mengaburkan lapisan atas dan bawahnya dengan memanfaatkan pergerakan [1].

Prinsip tomografi adalah mendapatkan gambaran yang lebih jelas dari suatu lapisan tertentu dengan menggerakkan dua diantara tiga komponen. Ketiga komponen tersebut adalah tabung, film dan objek. Umumnya, pesawat tomografi melakukan pergerakan dari tabung dan film secara berlawanan arah dan berputar di sekitar titik fulcrum (titik pivot) selama eksposi.Pergerakan ini dapat terjadi karena terdapatnya tiang logam yang terhubung pada pesawat tomografi. Selain itu, terdapatnya movable bucky di bawah meja pasien yang membuat pasien tidak akan merasa terganggu meskipun movable bucky itu bergerak selama eksposi. Simpangan yang terjadi pada saat tabung bergerak diukur berdasarkan kedalaman lapisan yang diinginkan sehingga nantinya menghasilkan sudut tomografi (tomographic angle/arc).

Bidang yang berada di titik fulcrum akan menghasilkan gambaran yang tajam karena pada titik itu tidak terjadi pergerakan selama eksposi sedangkan lapisan di sekitarnya mengalami pengaburan diakibatkan pergerakan. Karena itu, dalam tomografi ada dua hal yang harus diperhatikan yaitu, pengaturan film dan pengaturan fulcrum (titik pivot). Keselarasan pergerakan pada dua komponen tersebut yang menjadi pusat peregerakan pesawat tomografi.Karena itulah, komponen yang ada pada pesawat tomografi perlu didesain dengan baik dan mendapat perawatan berkala agar pengaturannya selalu baik.

Pada Gambar 1 dijelaskan mengenai prinsip dan teknik tomografi yaitu pada permulaan eksposi tabung dan film pada posisi T1 dan F1, lalu selama eksposi tabung akan bergerak berlawanan dengan film dan pergerakan keduanya akan berakhir pada posisi T2 dan F2.

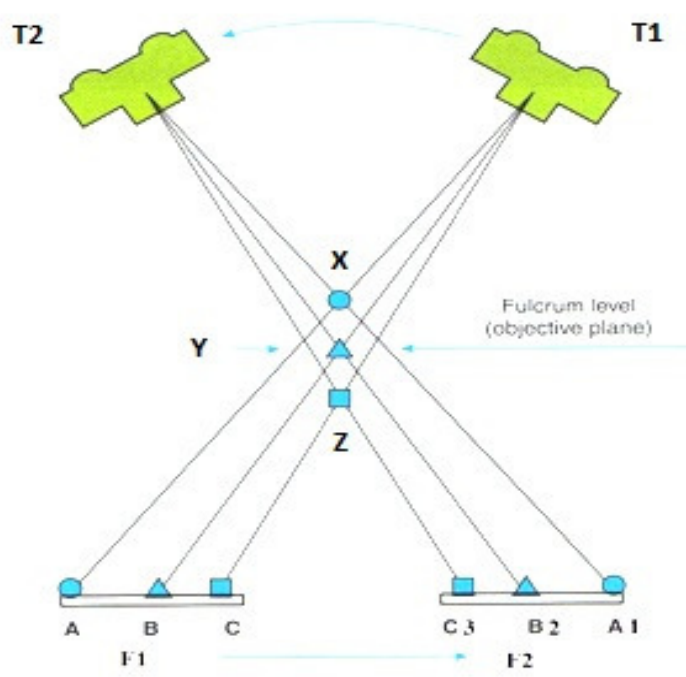

GAMBAR 1 Prinsip kerja tomografi [2].

Dosis serap adalah jumlah energi yang diserahkan oleh radiasi atau banyaknya energi yang diserap oleh bahan persatuan massa bahan itu. Jadi, dosis serap merupakan ukuran banyaknya energi yang diberikan oleh radiasi pengion kepada medium.Satuan untuk dosis serap adalah Joule perkilogram-medium (J.kg-1).Dalam sistem SI besaran dosis serap diberi satuan khusus, yaitu Gray $(G y)$. Persamaan dosis serap dijelaskan (1) [4].

$$
D=\frac{d E}{d M}
$$


Dengan $D=$ Dosis serap $(\mathrm{J} / \mathrm{kg}), d E=$ Jumlah energi $(\mathrm{J}) d M=$ Massa medium $(\mathrm{kg})$

Sebelum satuan SI digunakan, dosis serap diberi satuan rad (radiation absorbed dose), $1 \mathrm{rad}$ setara dengan $10^{-2}$ Gray atau 100 Gray setara dengan 1 rad.

Dosis ekivalen efektif atau yang bisa disebut dosis efektif. Hubungan antara peluang timbulnya efek biologi tertentu akibat penerimaan dosis ekivalen pada suatu jaringan bergantung pada organ atau jaringan yang tersinari. Untuk menunjukkan keefektifan radiasi dalam menimbulkan efek tertentu pada suatu organ diperlukan besaran baru yang disebut dosis efektif $\left(\mathrm{H}_{\mathrm{E}}\right)$. Besaran ini merupakan penurunan dari besaran dosis ekivalen yang dibobot. Dosis efektif dalam organ (T), yang menerima penyinaran dengan radiasi ekivalen ditentukan dengan persamaan 2 dan 3 sebagai berikut [4]:

$$
\begin{aligned}
& H_{E}=\sum W_{T} \cdot W_{R \cdot} D \\
& H_{E}=\sum W_{R} \cdot H_{T R}
\end{aligned}
$$

Dengan $H_{E}$ : Dosis ekivalen efektif (mSv), D: Dosis serap (mGy), $H_{T R}$ : Dosis ekivalen organ yang menerima penyinaran $(\mathrm{mSv}), W_{R}$ : Bobot radiasi, $W_{T}$ : Bobot jaringan $(\mathrm{mSv})$.

\section{METODE DAN BAHAN}

Penelitian ini dilakukan dengan menggunakan pesawat sinar-X merk Siemens dengan tipe Polydros L x 30 dibagian Instalasi Radiodiagnostik salah satu Rumah Sakit milik Pemerintah. Pesawat ini memiliki kapasitas $630 \mathrm{~mA} / 150 \mathrm{kV}$. Bahan dan peralatan lain yang digunakan Dosimeter Thermoluminensi Termal (TLD) 100 LiF beserta TLD reader harshaw 3500, Obyek phantom dan meteran.

Penelitian ini dilakukan dengan menempelkan TLD di sekitar tabung sinar-X sebanyak 8 lintasan dengan masing-masing jarak $50 \mathrm{~cm}, 100 \mathrm{~cm}$ dan $150 \mathrm{~cm}$.Penghitungan jarak sendiri dilakukan secara konsisten dari titik pusat (central point) pemeriksaan. Titik fulcrum yang digunakan sebesar $4 \mathrm{~cm}$ dengan kemiringan sudut tabung sebesar $30^{\circ}$. Pada Gambar 2 . diperlihatkan penempatan TLD dalam koordinat cartesius yang akan berbentuk seperti bujur sangkar berlapis.

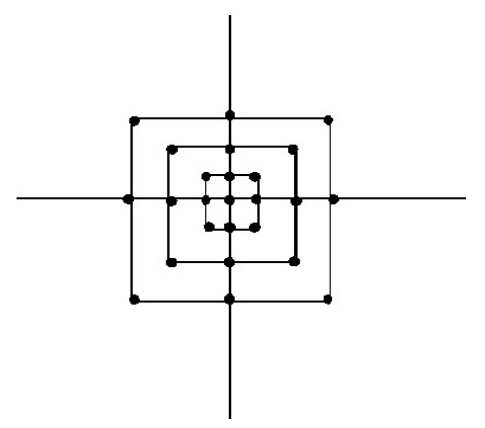

GAMBAR 2. Pemetaan TLD (Pribadi)

Dari hasil pengukuran yang didapat, akan didapatkan data berupa nilai dosis permukaan tomografi ginjal dan sebaran hamburan pesawat sinar-X tomografi. Kemudian, dari data dosis tersebut akan dianalisis dan dibuat dalam bentuk tabel. Dari tabel itulah akan dibentuk kontur sebaran radiasi hambur dengan bantuan perangkat lunak surfer. Kemudian dari kontur tersebut akan dianalisa pengaruh jarak terhadap sebaran.

\section{HASIL DAN PEMBAHASAN}

Proses pengukuran dilakukan dengan meletakkan TLD sesuai nomor urut yang sudah ditentukan di lintasan yang diinginkan seperti ditunjukkan pada Gambar 3. Penempatan TLD dilakukan 
dengan ketinggian yang sama dengan objek phantom. Proses penempatan TLD sendiri disesuaikan dengan nomor urut yang sudah tertera pada TLD. Selain terdapatnya lintasan, pada Gambar 4.1.juga ditunjukkan pengurutan peletakkan TLD sesuai nomor urutnya. Secara berurutan TLD ditempatkan di jarak $50 \mathrm{~cm}, 100 \mathrm{~cm}$ dan $150 \mathrm{~cm}$ secara konsisten dihitung dari titik pusat (central point) pemeriksaan.

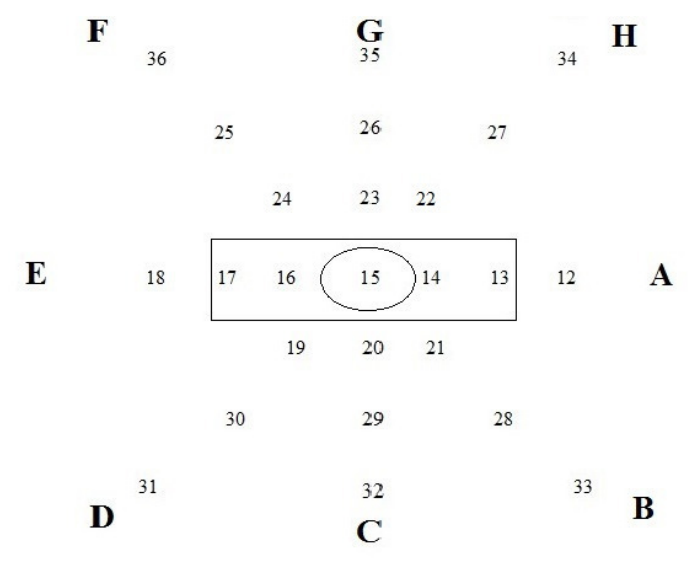

GAMBAR 3 Denah peletakkan TLD sesuai nomor urut

Pada tabel 1 ditunjukkan hasil pengukuran paparan radiasi hambur dengan menggunakan TLD.Pada TLD dengan nomor urut 15 berada pada permukaan objek. TLD ini ditempatkan pada titik pusat (central point) pemeriksaan tomografi ginjal. Dengan meletakkan TLD di titik pusat pemeriksaan ini nantinya juga akan didapatkan nilai dosis permukaan dalam sekali pemeriksaan tomografi ginjal.

TABEL 1. Hasil pengukuran pemetaan hamburan pesawat tomografi

\begin{tabular}{|r|r|r|r|}
\hline $\begin{array}{c}\text { No. } \\
\text { TLD }\end{array}$ & $\begin{array}{c}\text { Koordinat } \\
(\mathrm{x}, \mathrm{y})\end{array}$ & $\begin{array}{c}\text { Jarak } \\
(\mathrm{cm})\end{array}$ & \multicolumn{1}{c|}{ Dosis $(\mu \mathrm{Gy})$} \\
\hline 12 & $(0,-3)$ & 150 & 7,60 \\
\hline 13 & $(0-2)$ & 100 & 17,63 \\
\hline 14 & $(0,-1)$ & 50 & 59,95 \\
\hline 15 & $(0,0)$ & 0 & 136,87 \\
\hline 16 & $(0,1)$ & 50 & 35,50 \\
\hline 17 & $(0,2)$ & 100 & 16,50 \\
\hline 18 & $(0,3)$ & 150 & 13,94 \\
\hline 19 & $(-1,1)$ & 50 & 114,04 \\
\hline 20 & $(-1,0)$ & 100 & 21,83 \\
\hline 21 & $(-1,-1)$ & 150 & 38,54 \\
\hline 22 & $(1,-1)$ & 50 & 44,15 \\
\hline 23 & $(1,0)$ & 50 & 9,44 \\
\hline 24 & $(1,1)$ & 50 & 66,50 \\
\hline 25 & $(2,2)$ & 100 & 19,63 \\
\hline 26 & $(2,0)$ & 100 & 6,59 \\
\hline 27 & $(2,-2)$ & 100 & 11,03 \\
\hline 28 & $(-2,-2)$ & 100 & 21,64 \\
\hline 29 & $(-2,0)$ & 100 & 8,45 \\
\hline 30 & $(-2,2)$ & 100 & 58,52 \\
\hline 31 & $(-3,3)$ & 150 & 15,67 \\
\hline 32 & $(-3,0)$ & 150 & 2,42 \\
\hline 33 & $(-3,-3)$ & 150 & 6,28 \\
\hline 34 & $(3,-3)$ & 150 & 4,90 \\
\hline 35 & $(3,0)$ & 150 & 4,02 \\
\hline 36 & $(3,3)$ & 150 & 4,74 \\
\hline
\end{tabular}

Berdasarkan pengukuran yang sudah dilakukan, dosis permukaan yang diterima pasien dalam sekali pemeriksaan tomografi adalah sebesar 0,13687 mGy. Dari pengukuran ini didapatkan dosis efektif sebesar $0,028 \mathrm{mSv}$ untuk jaringan gonad dan $0,007 \mathrm{mSv}$ untuk organ ginjal. Dari hasil pengukuran dan pemetaan yang ada pada gambar 4 didapatkan nilai sebaran hamburan dari 
kedelapan lintasan yang ada pada jarak $50 \mathrm{~cm}$ didapatkan nilai paparan radiasi terbesar berada pada depan tabung pesawat sinar-X dekat kepala pasien (titik D1) yang besarnya $114,04 \mu \mathrm{Gy}$. Diikuti dengan area di belakang dan kaki pasien (titik F1), kemudian di kaki pasien (titik A1), lalu di belakang tabung dekat kaki (titik H1), kemudian di depan tabung dekat kaki (titik B1), lalu di kepala pasien (titik E1), kemudian diikuti di depan tabung sinar-X (titik C1) sedangkan nilai terkecil berada di belakang tabung sinar-X dekat tiang penyangga tabung (titik G1) dengan nilai $9,44 \mu \mathrm{Gy}$.

Pada jarak $100 \mathrm{~cm}$ atau $1 \mathrm{~m}$ nilai terbesar tetap tercatat pada area depan tabung sinar-X dekat kepala pasien (titik D2) dengan nilai 58,52 $\mu$ Gy. Kemudian, berturut-turut berada di depan tabung sinar-X dekat kaki pasien (titik B2), diikuti dengan belakang tabung dekat kepala pasien (titik F2), diikuti dengan area di kaki pasien (titik A2), diikuti dengan area di kepala pasien (titik E2), lalu di belakang tabung sinar-X dekat kaki pasien (titik H2), diikuti dengan depan tabung sinar-X (titik C2) dan untuk nilai terkecil masih berada di belakang tabung sinar-X dekat tiang penyangga tabung (titik G2) dengan nilai $6,59 \mu \mathrm{Gy}$.

Untuk jarak $150 \mathrm{~cm}$ atau $1,5 \mathrm{~m}$ nilai terbesar berada di depan tabung sinar-X dekat kepala pasien (titik D3) dengan nilai 15,670 $\mu \mathrm{Gy}$. Berikutnya, berada di samping tabung sinar-X dekat kepala pasien (titik E3) kemudian di kaki pasien (titik A3), lalu di depan tabung (titik B3), di belakang tabung dekat kaki pasien (titik H3), lalu di belakang tabung dekat kepala (titik F3) dan berada di belakang tabung dekat tiang penyangga (titik G3) sedangkan nilai terkecil berada di depan tabung sinar-X (titik C3) menjadi titik dengan nilai terkecil dengan nilai 2,42 $\mu \mathrm{Gy}$.

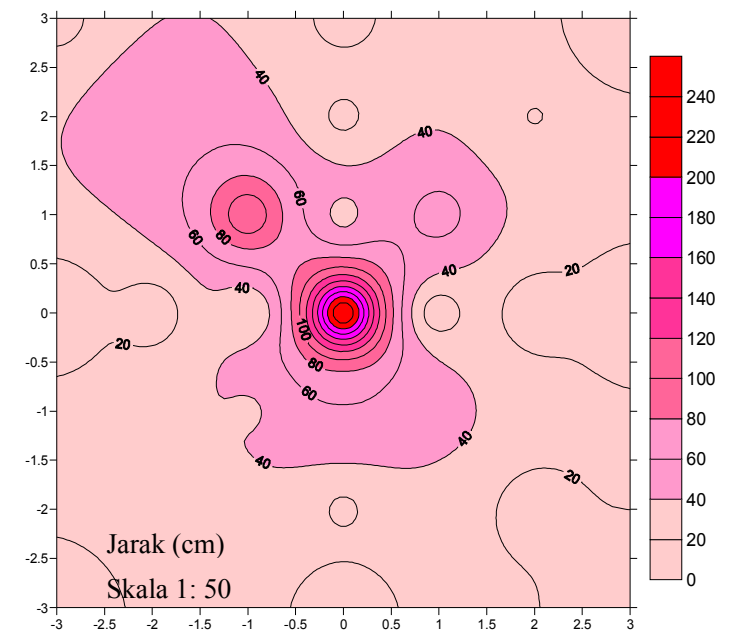

Gambar 4 Pemetaan hamburan radiasi pesawat tomografi

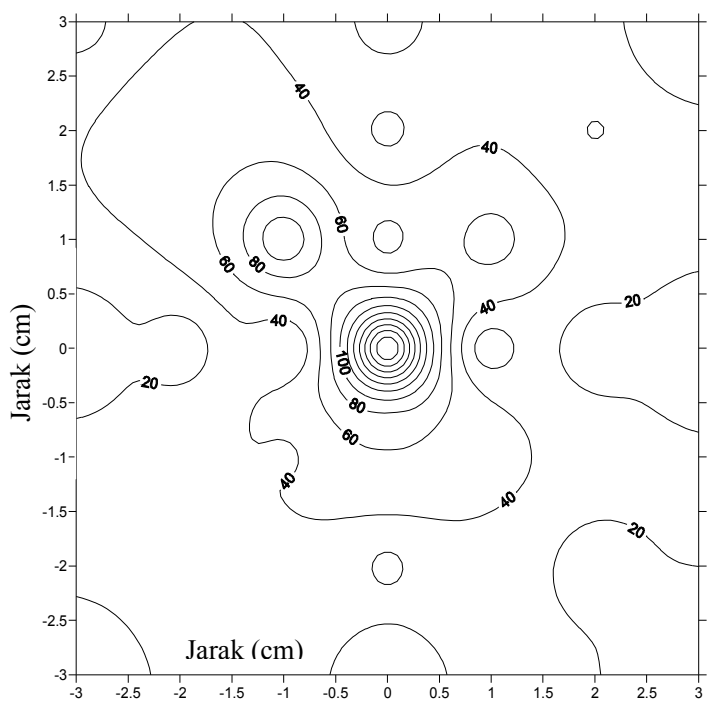

GAMBAR 5. Kontur hamburan pesawat tomografi 
Kontur yang dibentuk pada gambar 5 di atas dengan pemilihan gradasi warna merah muda (pink).Pada kontur yang telah dibentuk oleh surfer pada gambar 5 dapat dilihat nilai sebaran radiasi tertinggi berada pada meja pemeriksaan (titik O) dengan rentang nilai 240-220 $\mu$ Gy yang ditandai dengan warna merah. Kemudian dengan rentang nilai 120-80 $\mu$ Gy berada pada depan tabung sinar-X (titik D1) pada jarak $50 \mathrm{~cm}$ dengan area tersebut diberi warna merah muda yang agak tua (deep pink) pada kontur. Dengan rentang 60-40 $\mu$ Gy berada pada belakang tabung sinar-X (titik F) ditunjukkan dengan area tersebut berwarna merah muda (pink).Umumnya, sebaran radiasi pada rentang 60-40 $\mu$ Gy mengelilingi jarak $50 \mathrm{~cm}$ seperti yang ditunjukkan pada gambar 5.Diikuti dengan rentang 40-20 $\mu$ Gy yang sudah mengelilingi area pemeriksaan diberi warna merah muda (pink).Pada rentang ini jarak yang dimiliki sudah berada sekitar $1 \mathrm{~m}$ dari sumber radiasi.Pada area ini sebaran sudah semakin menurun seiring semakin jauhnya dari sumber radiasi. Sedangkan, pada jarak 1,5 m semua area sudah memiliki nilai sebaran radiasi dengan rentang 20-0 $\mu$ Gy seperti ditunjukkan dengan warna merah muda (pink).

\section{KESIMPULAN}

Dari penelitian yang telah dilakukan dapat disumpulkan bahwa dalam setiap pemeriksaan tomografi ginjal didapatkan dosis permukaan sebesar 0,137 mGy. Dari hasil pengukuran yang ada dari kedelapan lintasan yang ada pada jarak $50 \mathrm{~cm}, 100 \mathrm{~cm}$ dan $150 \mathrm{~cm}$ didapatkan nilai paparan radiasi terbesar selalu berada pada depan tabung pesawat sinar-X (titik D1, D2 dan D3) berturut-turut dengan nilai $114,04 \mu \mathrm{Gy} ; 58,52 \mu \mathrm{Gy} ; 15,670 \mu \mathrm{Gy}$. Sedangkan berdasarkan pengukuran yang dilakukan nilai terkecil dari kedelapan lintasan tersebut berada pada depan tabung sinar-X (titik C3) dengan nilai 2,42 $\mu$ Gy pada jarak $150 \mathrm{~cm}$. Dari pemetaan kontur yang sudah dilakukan surfer terlihat lokasi-lokasi yang memiliki wilayah hamburan paling besar serta paling kecil. Dari hasil pengamatan, area kepala pasien baik itu di depan ataupun belakang tabung sinar-X (lintasan D dan F) memiliki nilai terbesar dengan rentang 120-60 $\mu \mathrm{Gy}$. Ini mungkin disebabkan karena dengan berada di depan dan belakang tabung akan semakin dekat dengan sumber radiasi. Selain itu, saat eksposi berlangsung tabung tomografi memiliki kemiringan tertentu sehingga membuat radiasi yang menyebar lebih besar, ditambah dengan tidak adanya medium penghalang pada lintasan ini yang membuat sebaran radiasi hambur lebih besar tanpa ada penyerapan terlebih dahulu oleh medium penghalang manapun.

\section{REFERENSI}

[1] Carlton, R. R. (1992). Principles of Radiographic Imaging: An Art and Science. New York: DelmarP[ublisher.

[2] Bontrager, K. L. (2005). Textbook of Radiographic Positioning and Related Anatomy. St. Louis: CV. Mosby.

[3] Wiryosimin,S. (1991).Mengenal Asas Proteksi Radiasi.Bandung:Penerbit ITB.

[4] Akhadi, M. (2000). Dasar-Dasar Proteksi Radiasi Edisi I. Jakarta: Rineka Cipta.

[5] Kevles, B. (1997). Naked the Bone: Medical Imaging in the Twentieth Century. New Brunswick: Rutgers University Press.

[6] Chesney, M. D., dan Chesney, M. O. (1992). X-Ray Equipment for Student Radiographer. Philadelphia: Blackwell Scientific Publications.

[7] Meredith, W. J. \& Massey, J. B. (1977). Fundamental Physics of Radiology. Chicago: John Wright \& Sons Ltd Publishing.

[8] Komisi Proteksi Radiasi Kawasan Nuklir Serpong BATAN. (2011). Pedoman Keselamatan dan Proteksi Radiasi Kawasan Nuklir Serpong Revisi 1. Jakarta: BATAN.

[9] http://www.goldensoftware.com/products/surfer diakses pada tanggal 14 Maret 2014 pukul 14:09

[10] Harinaldi, M. (2005). Prinsip-Prinsip Statistik Untuk Teknik dan Sains . Jakarta: Erlangga. 
[11] http://www.rpdinc.com/tld-100-ribbons-chips-package-of-100-311.html diakses pada tanggal 20 April 2014 pukul 17:10

[12] http://www.thermoscientific.com/en/product/harshaw-tld-model-3500-manual-readers 1.html diakses pada tanggal 20 April 2014 pukul 17:15

[13] Krane, K. (1992). Fisika Modern. Jakarta: Universitas Indonesia Press.

[14] http://ejournal.undip.ac.id/index.php/berkala_fisika/article/download/4997/4530 diakses pada tanggal 20 Desember 2013 pukul 15:10

[15] Attix, F. H. (1986). Introduction to Radiological Physics and Radiation Dosimetry. New York: Wiley-VCH. 